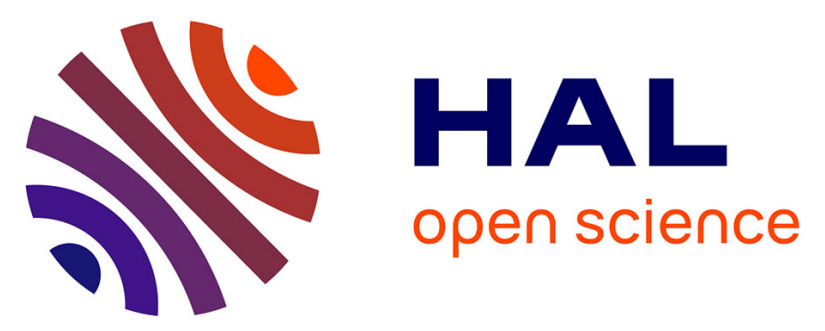

\title{
Look ahead of the bit while drilling: potential impacts and challenges of acoustic seismic-while-drilling in the McMurray Formation
}

Siavash Nejadi, Nasser Kazemi, Jordan Curkan, Jean Auriol, Paul Durkin, Stephen Hubbard, Kristopher Innanen, Roman J. Shor, Ian Gates

\section{To cite this version:}

Siavash Nejadi, Nasser Kazemi, Jordan Curkan, Jean Auriol, Paul Durkin, et al.. Look ahead of the bit while drilling: potential impacts and challenges of acoustic seismic-while-drilling in the McMurray Formation. Society of Petroleum Engineers Journal, 2020, 10.2118/199931-pa . hal-02732927

\section{HAL Id: hal-02732927 \\ https://hal.science/hal-02732927}

Submitted on 2 Jun 2020

HAL is a multi-disciplinary open access archive for the deposit and dissemination of scientific research documents, whether they are published or not. The documents may come from teaching and research institutions in France or abroad, or from public or private research centers.
L'archive ouverte pluridisciplinaire HAL, est destinée au dépôt et à la diffusion de documents scientifiques de niveau recherche, publiés ou non, émanant des établissements d'enseignement et de recherche français ou étrangers, des laboratoires publics ou privés. 


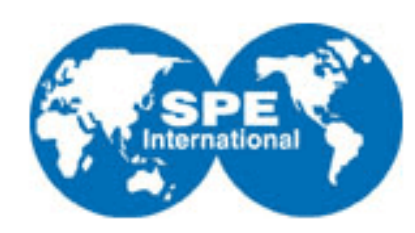

\section{Look ahead of the bit while drilling: potential impacts and challenges of acoustic seismic-while-drilling in the McMurray Formation}

\begin{tabular}{|r|l|}
\hline Journal: & SPE Journal \\
\hline Manuscript ID & SJ-0120-0022.R2 \\
\hline Danuscript Type: & Technical Paper \\
\hline Author: & $18-$ May-2020 \\
\hline & $\begin{array}{l}\text { Complete List of Authors: } \\
\text { Aurkan, Jean; Université Paris-Saclay } \\
\text { Durkin, Paul; University of Manitoba } \\
\text { Hubbard, Stephen; University of Calgary, Geoscience } \\
\text { Innanen, Kristopher ; University of Calgary, Geoscience } \\
\text { Shor, Roman; University of Calgary, schulich school of engineering } \\
\text { Gates, Ian; University of Calgary, Chemical and Petroleum Engineering }\end{array}$ \\
\hline Keywords: & $\begin{array}{l}\text { Seismic while Drilling, McMurray Formation, well placement, steam } \\
\text { assisted gravity drainage (SAGD), blind deconvolution }\end{array}$ \\
\hline & \\
\hline
\end{tabular}

\section{SCHOLARONE ${ }^{\text {m }}$ \\ Manuscripts}




\title{
SPE-199931
}

\section{Look ahead of the bit while drilling: potential impacts and challenges of acoustic seismic-while-drilling in the McMurray Formation}

\author{
Siavash Nejadi, University of Calgary; Nasser Kazemi, University of Calgary; Jordan A. Curkan, University of \\ Calgary; Jean Auriol, Université Paris Saclay, CNRS, CentraleSupelec (L2S); Paul R. Durkin, University of \\ Manitoba; Stephen M. Hubbard, University of Calgary; Kristopher A. Innanen, University of Calgary; Roman J. \\ Shor, University of Calgary; Ian Donald Gates, University of Calgary;
}

\section{Summary}

The oil and gas industry, operating and service companies, and academia are actively looking for ways to see ahead of the drillbit while drilling to reduce the risks and costs of the operation and improve the wellplacement process. Optimal drilling in challenging and highly heterogeneous reservoirs, where geological data cannot adequately constrain high-frequency variations in rock properties, requires reliable subsurface information from around and ahead of the drillbit. To provide this, we have developed a seismic-whiledrilling imaging algorithm based on signal processing, drillstring modeling, and pre-stack wave-equation migration.

To extend the visibility ahead-of-the-bit, we use the drillbit as a seismic source and image the changes in acoustic properties of rocks both around and ahead of the drillbit. The common practice is to build reverse vertical seismic profile (R-VSP) gathers. Here, we use a blind deconvolution algorithm to estimate the drillbit source signature from the data directly. Alternatively, we can estimate such a signature through drillstring modeling and surface measurements (i.e., hookload and hook speed). The drillstring dynamics are modeled and analyzed by using Riemann's invariants and a backstepping approach in a field-verified model. Next, we input the estimated source signature to the pre-stack wave-equation depth imaging workflow. Our simulations show that providing the drillbit source signature to the pre-stack wave equation depth migration consistently delivers reliable subsurface images around and ahead of the drillbit.

The output of our workflow is a high-resolution subsurface image, which is then applied to provide vital information in oil sands reservoirs for placement of steam assisted gravity drainage (SAGD) well pairs. Compared to conventional practices, the proposed methodology images around and ahead of the drillbit enabling interactive decision making and optimal well-placement. The key feature of the presented methodology is that instead of cross-correlating the seismic-while-drilling data with the pilot trace and building R-VSP gathers, we use the estimated drillbit source signature and deliver high-resolution prestack depth migrated images.

Through numerical modeling, we tested the potential impacts, validity, and challenges of the proposed methodology in drilling horizontal wells in SAGD settings with an emphasis on the McMurray Formation. We further compared the results with the conventional drilling practice. In contrast to existing tools that have limited depth of penetration, interpreting seismic-while-drilling data in real-time confidently maps key target features ahead of the drillbit. This imaging workflow provides sufficient time to precisely control the borehole trajectory and stay within the desired reservoir zone. Accordingly, it mitigates the risk of intersecting mudstone-filled channels and lean zones.

\section{Introduction}

The Lower Cretaceous McMurray Formation hosts the majority of bitumen in the Athabasca oil sands the largest known resource of bitumen. This formation is composed of large-scale point bars and other components of meander-belts that are highly heterogeneous (Musial et al. 2012; Durkin et al., 2017). 
Repeated erosional events that took place during overall accumulation of the McMurray Formation have led to multi-stacked channel-belt deposits (Hein and Cotteril 2013; Horner et al. 2019). Associated point bar deposits are up to $50 \mathrm{~m}$ thick, and often exhibit thick packages of massive to cross-stratified sandstones near their base and interbedded sandstones and siltstones upwards (Durkin et al., 2017), which are referred to as inclined heterolithic strata (IHS) (Thomas et al. 1987). More broadly, channel-belt deposits consist of an amalgam of depositional elements, resulting in complex sedimentary facies relationships, where rock types vary both laterally and vertically over short distances (e.g., Hubbard et al. 2011).

Steam-Assisted Gravity Drainage (SAGD) (Butler 1982) is the most promising in-situ recovery process to produce bitumen resources from Athabasca oil-sands deposits (Butler 1991; Strobl et al. 1997). SAGD well configurations typically consist of two parallel horizontal wells located a short distance apart, one above the other. The length of horizontal sections ranges from 500 to $1000 \mathrm{~m}$, and the vertical separation is 5-7 m. As the name implies, the key production mechanism in SAGD is gravity. Hence, placing the producing well at non-optimal elevations (i.e., too high) reduces the ultimate recovery factor. Bitumen below the production well cannot be recovered at any significant distance from the well and therefore placement at or near the base of porosity is optimal. Another significant design limitation worth noting is controlling the borehole undulation, with less than $0.5 \mathrm{~m}$ unwanted horizontal deviations over its entire length targeted (i.e. $0.5 / 1000 \mathrm{~m}$ ).

Geological interpretations of the subsurface, together with engineering design, determine the optimal placement of the horizontal wells. In SAGD systems, the optimal field development requires not only an estimation of gross reservoir thickness but also the distribution of non-reservoir facies and connectivity. Fluvial processes related to point bar formation, intra-point bar erosion, counter-point bar formation, and channel abandonment contribute to the development of heterogeneities within the McMurray Formation (Thomas et al. 1987; Hubbard et al. 2011; Martinius et al. 2017; Yan et al. 2017; Durkin et al. 2017). Bedding architecture and lithologic heterogeneities in different geobodies influence the connected hydrocarbon volume and recovery performance. Mapping IHS muddy abandoned channel fills, where possible, improves the understanding of flow barriers and baffles in the reservoir. This aid both well placement and advanced well completion design for improved recovery.

The use of three-dimensional (3D) seismic data for detailed subsurface interpretation is a common practice (e.g., Hubbard et al. 2011; Durkin et al. 2017). 3D seismic data, a high density of wells and extensive cores are used to infer characteristics of sedimentary architecture, including the geometry of point bar elements. The workflow relies on the combination of data types to construct high-resolution geological models of channelized reservoirs, which are the basis of development strategies. The elements of meanderbelt deposits at different stratigraphic levels of the reservoir are deterministically modeled and combined with methodologies to infer reservoir rock parameters, such as facies and porosity trends, using seismic attributes (Journel 2002).

In general, several factors affect the resolution of seismic data. A 360-degree seismic ray path coverage is required to have an ideal and reliable seismic image of the subsurface. The 360-degree coverage guarantees uniform sampling and illumination of the subsurface structure. However, in the field, we only have access to seismic recordings at the surface. The complex stratigraphic architecture, high heterogeneity, low impedance contrast, and sub-seismic features introduce non-uniform illumination and uncertainties in seismic images. In the point-bar deposits of the McMurray Formation, the presence of sub-seismic mudstone drapes potentially impedes steam chamber growth (Richardson et al. 1978; Hartkamp-Bakker and Donselaar 1993). These mudstone drapes cannot be imaged using surface seismic methods. Moreover, the deposits towards the base of the reservoir overlying the sub-Cretaceous unconformity surface are convoluted and typically have a low impedance contrast, which makes detailed imaging of stratigraphic architecture difficult. The small-scale heterogeneities, convoluted layers, and irregular surface topography of the underlying sub-Cretaceous unconformity contribute to stratigraphic 
complexity and result in a poor seismic response in the region. To reduce the uncertainties inherent in surface seismic recordings, we need to use other sources of information.

Conventional SAGD well placement practice includes acquiring data while drilling for optimal placement of the laterals. Measurement-while-drilling (MWD) and logging-while-drilling (LWD) have been adopted to monitor drilling parameters and acquire formation properties, in real-time, and transfer data to the surface. Applications of MWD systems include monitoring and controlling the directional-drilling operation, assistance in detection of abnormal pressure zones, correlation logging, preliminary evaluation of some possible producing zones, and monitoring of weight-on-bit (WOB) and drilling torque at the bit (Dowell et al. 2006). Accurate measurements of depth, inclination, and azimuth are essential for the path determination of horizontal SAGD wells. Among various LWD tools such as gamma ray (GR), nuclear, acoustic, or NMR technologies, LWD resistivity measurements are the principal measurement for geosteering and optimal well placement; the depth of investigation of LWD resistivity tools is significantly larger than that of any other LWD tools (Upchurch et al. 2016; Thiel et al. 2019). LWD tools have sensors located immediately above or near the drillbit. Placing these near the bit provides an opportunity to first detect, and then avoid drilling into non-reservoir, which is a pseudo-look-ahead capability.

To place the wells in the best possible reservoir section, operators exploit look-ahead monitoring techniques to guide real-time well trajectory adjustment. Methods to use noise generated by the drillbitrock interaction and monitor the rock properties ahead of the drillbit have been investigated since the 1960s (Poletto and Miranda 2004). The drillbit-rock interaction generates significant $\mathrm{P}$ and $\mathrm{S}$ waves that are strong enough to reflect off of subsurface layer boundaries and be recorded at the surface or in nearby wells. The methodology that uses the seismic waves generated by the drillbit-rock interaction to image the subsurface structure is called seismic-while-drilling (SWD) imaging. Authors also refer to SWD imaging as reverse vertical seismic profiling (R-VSP) (Hardage 1985; Poletto and Miranda 2004). This is because in VSP recordings, the seismic source is at the surface, and the recording devices (i.e., geophones), are placed in the wells. However, in SWD data, the drillbit-rock interaction in the well acts as a seismic source, and the geophones record drillbit noise at the surface. Previous work on SWD imaging relies on cross-correlating the recorded SWD data with the pilot trace and building the R-VSP gathers (Rector and Marion 1991). This method has been successfully implemented for field applications. Using R-VSP results in high-resolution imaging of the subsurface structure around the borehole. However, imaging the R-VSP gathers does not provide insight into rock properties.

SWD has some advantages over LWD and VSP methods. LWD measurements are made behind the bit whereas SWD-based algorithms image around and ahead of the bit. Imaging ahead of the bit provides an opportunity to adjust the drilling parameters, for example, improving the rate of penetration (ROP) and updating the well trajectory. This, in turn, ensures staying in the sweet spot, and avoiding risky and nonproducible zones. Also, compared to VSP, the SWD method does not interfere with drilling. Accordingly, the drilling crew can drill wells and record drillbit noise simultaneously (Poletto and Miranda 2004). Besides, in SWD, there is the option to record drillbit noise in nearby wells, allowing imaging between wells (i.e., crosswell imaging). Crosswell imaging using SWD gives vital information about nearby subsurface structures through the development process (Justice et al. 1989; Washbourne et al. 2002; Zhang et al. 2007). In other words, crosswell images improve reservoir characterization and are used to optimize subsequent well pair/pad placement.

The main focus of this study is to present a SWD methodology supported by several case studies inspired from the Surmont SAGD project in northeastern Alberta, Canada. We investigate potential applications of look-ahead-of the-bit information for an improved well pad drilling approach. The approach helps to reduce drilling risks and improves 1) the geosteering decisions for individual production wells including their vertical placement and 2) the knowledge of geological heterogeneity and reservoir boundaries in well pad design. The computational requirements of the methodology would not constrain its implementation for real-time operational decision making. The methodology provides high-resolution ahead-of-the-bit 
images of the subsurface that identify reservoir boundaries and highlight geological heterogeneities to be used for real-time decision making.

\section{Methodology}

Drillbit-rock interaction generates significant elastic energy in the subsurface. The drillbit energy propagates through or reflects from subsurface layers, and can commonly be recorded at the surface or nearby wells. These seismic waves follow the wave equation (Chapman 2004)

$$
\left(\omega^{2} \mathbf{s}^{2}+\nabla^{2}\right) P=f \delta\left(\mathbf{x}-\mathbf{x}_{s}\right)
$$

where $P$ is pressure wavefield, $\boldsymbol{s}$ is slowness, $\omega$ is temporal frequency, $f$ is the drillbit source signature, $\mathbf{x}_{\mathbf{s}}$ is source location, $\nabla^{2}$ is Laplacian operator, and $\delta$ is the Dirac delta function. Solving the wave equation represented in Equation-1 provides the information necessary to generate a subsurface image. To solve Equation-1, we use the Born approximation (Born 1926). We decompose the subsurface slowness and recorded pressure wavefield as follows

$$
\mathbf{s}^{2}=\mathbf{s}_{0}^{2}+\mathbf{m}, \text { and } P=P_{0}+\Delta P
$$

where $\mathbf{s}_{0}$ is the background slowness, $\mathbf{m}$ is the subsurface image, $P_{0}$ is the pressure wavefield satisfying the background medium, and $\Delta P$ is the perturbation in the pressure wavefield due to $\mathbf{m}$. Then, by using the Born approximation (Born 1926), we obtain the subsurface image as

$$
\mathbf{m}(\mathbf{x})=-\sum_{\omega} \sum_{\mathbf{x}_{s}^{\prime}} \sum_{\mathbf{x}_{r}^{\prime}}\left(\omega^{2} P_{0}^{*}\left(\mathbf{x}, \omega ; \mathbf{x}_{s}^{\prime}\right) G_{0}^{*}\left(\mathbf{x}_{s}^{\prime}, \mathbf{x}_{r}^{\prime}, \omega ; \mathbf{x}\right) d\left(\mathbf{x}_{r}^{\prime}, \mathbf{x}_{s}^{\prime}, \omega\right)\right)
$$

where $d$ is the recorded SWD data at the surface, $G_{0}$ is the Green's function that satisfies the wave equation in the background medium, $\mathrm{x}_{\mathrm{s}}^{\prime}$ is source location, $\mathrm{x}_{\mathrm{r}}^{\prime}$ is receiver location, and $P_{0}$ is the source-side wavefield. To generate the source-side wavefield, the drillbit source signature is estimated through the exploration of two methodologies.

The first method uses a signal processing algorithm and directly estimates the drillbit source signature from the recorded SWD data. We use a multichannel blind deconvolution method, the SMBD algorithm (Kazemi and Sacchi 2014; Kazemi et al. 2018), to estimate the source signature directly from the data. It is a data-driven method that eliminates the need for recording the pilot trace.

Blind decovolution is an ill-posed problem and may result in non-unique solutions. To remedy this shortcoming, the SMBD algorithm employs a sparsity-promoting regularization function for the inversion process and provides unique solutions. The performances and sensitivity analysis of the SMBD algorithm have been discussed in Kazemi and Sacchi (2014). Moreover, Kazemi et al. (2018) show that the SWD imaging algorithm can tolerate, to some extent, the discrepancy between the true and estimated dill bit source signature. For example, the algorithm can estimate the drillbit source signature with the normalized correlation coefficient of 0.86 , and still successfully image the subsurface structure.

In the SMBD algorithm, data is modeled as the convolution of drillbit source signature with a reflectivity series

$$
\mathbf{d}_{j}=\mathbf{F} \mathbf{r}_{j}+\mathbf{n}_{j} \quad j=1, \ldots J
$$

where $\mathbf{F}$ is the convolution matrix built from the drillbit source signature $f, \mathbf{r}_{\mathrm{j}}$ and $\mathbf{n}_{\mathrm{j}}$ are the reflectivity series and noise term in channel $j$. Kazemi and Sacchi (2014) found the smallest common factor between the channels by solving an inverse problem where the solution fits the heterogeneous system of equations and provides a sparse reflectivity series. Then, the byproduct of the algorithm is the drillbit source signature. The SMBD algorithm estimates the smallest common factor between all of the channels in the 
SWD data by solving a heterogeneous system of equations. Convolving the data of channel $p$ with the reflectivity of channel $q$ and the data of channel $q$ with the reflectivity of channel $p$. After some algebraic manipulations, we get

$$
\mathbf{D}_{p} \mathbf{r}_{q}-\mathbf{D}_{q} \mathbf{r}_{p}=\mathbf{N}_{p} \mathbf{r}_{q}-\mathbf{N}_{q} \mathbf{r}_{p}
$$

where $\mathbf{D}_{\mathbf{p}}$ and $\mathbf{N}_{\mathbf{p}}$ are the convolutional matrices built from $d_{p}$ and $n_{p}$, respectively. After using all of the combinations similar to Equation-5 between all of the channels, we end up having a heterogeneous system of equations

$$
\mathbf{A y}=\mathbf{e}
$$

where

$$
\mathbf{A}=\left(\begin{array}{ccccccc}
\mathbf{D}_{2} & -\mathbf{D}_{1} & & & & & \\
\mathbf{D}_{3} & & -\mathbf{D}_{1} & & & \\
\mathbf{D}_{4} & & & -\mathbf{D}_{1} & & \\
\vdots & & & & \ddots & \\
& \mathbf{D}_{3} & -\mathbf{D}_{2} & & & \\
& \mathbf{D}_{4} & & -\mathbf{D}_{2} & & & \\
& \vdots & & & \ddots & & \\
& & & & \mathbf{D}_{J} & & -\mathbf{D}_{J-2} \\
& & & & & \mathbf{D}_{J} & -\mathbf{D}_{J-1}
\end{array}\right)
$$

and

$$
\mathbf{y}=\left[\mathbf{r}_{1}, \mathbf{r}_{2}, \mathbf{r}_{3}, \ldots, \mathbf{r}_{J}\right]^{T}
$$

The term $\mathbf{e}$ is the concatenation of vectors similar to the right-hand side of Equation- 6 . To find the reflectivity series that fit the heterogeneous system of equations represented in Equation-6, SMBD solves the following cost function

$$
\hat{\mathbf{y}}=\underset{\mathbf{y}}{\operatorname{argmin}} \frac{1}{2}\|\mathbf{A} \mathbf{y}\|_{2}^{2}+\lambda \sum_{i}\left(\sqrt{y_{i}^{2}+\epsilon^{2}}-\epsilon\right), \quad \text { subject to } \quad \mathbf{y}^{T} \mathbf{y}=1
$$

where $\lambda$ is a regularization parameter, and $\epsilon$ is a small number. The regularization term in the cost function is the Huber norm that promotes sparsity in the final solution. After finding the sparse reflectivity series, the drillbit source signature is estimated by a least-squares matching filter in the frequency domain that matches the data to the reflectivity series.

The second approach for estimating the drillbit source signature relies on drill string modeling and topdrive measurements (Auriol et al. 2020). These authors showed that through modeling the drillstring dynamics and measuring the surface axial force (hookload) and velocity (hook speed) time series, it is possible to estimate the drillbit source signature. They also use the estimated drillbit source signature in combination with the SWD data to estimate the velocity of rocks that are interacting with the drillbit.

In this paper, we assume that the drillbit generates significant energy that can reflect several times from layer boundaries, which can be recorded at the surface or nearby wells. Precautions are needed to adopt the suggested technique such as the optimum RPM, type of mud to be used, maximum allowable temperature of the drill string or any other parameter affecting the performance of SWD. However, in situations where the drillbit does not generate significant noise, we should consider using a controlled source in the well (e.g., Paulsson 1987). In both cases, i.e., using drillbit as a source or a controlled source, 
if the elastic energy reaches the surface or nearby wells, our proposed workflow is valid and provides high-resolution subsurface images.

\section{Case Studies}

This section presents different case studies where the look-ahead-while-drilling could potentially improve SAGD well placement. The main objective is to assess value creation as a result of using SWD to sequential geosteering decisions. We illustrate the application of the proposed methodology in various geological settings from the Surmont oil sands project.

The Surmont Lease study area in the Athabasca Oil Sands is located $\sim 70 \mathrm{~km}$ southeast of the city of Fort McMurray, Alberta, Canada (Figure-1A). A typical vertical profile of the McMurray Formation in the focused project area generally shows an overall fining upward sequence composed of a series of smaller upward fining cycles. It consists of a thick meander-belt deposit underlain by one or more incompletely preserved channel belt deposits. In the study area, a thin regionally deposited fine-grained sandstone and siltstone cover the upper meander-belt deposit. The top of the reservoir (cap rock) is a regionally correlatable marine flooding surface at the base of the Wabiskaw Member, which serves as the stratigraphic datum (Figure-1B, C).

High quality 3D seismic time-slices provide geometric constraints on the uppermost meander-belt depositional elements of the McMurray Formation (Durkin et al. 2017). It captures the 3D representation of these different depositional elements, or geobodies, including distinctive point bar ( $\mathrm{PBa}$ and $\mathrm{PBb})$ and counter-point bar (CPB) elements, side bars ( $\mathrm{SBa}, \mathrm{SBb}$, and $\mathrm{SBc}$ ), and abandoned channel fills (AC) (Figure-2). In this seismically-constrained meander-belt deposit, we deterministically model the individual depositional elements; these stationary zones constrain parameter estimations in the property modeling phase (Nejadi et al. 2019). The point bar and counter-point bar elements contain sandstones near their base and varied proportions of interbedded sandstone and siltstone (IHS) upwards. The side bars are mainly composed of sandstone with proportionally less IHS. The abandoned channel is dominated by siltstone.

Optimal SAGD development requires not only an estimation of the gross oil-sand reservoir thickness, but also internal imaging of the reservoir, including the distribution of non-reservoir facies. Current best practice for SAGD well pad placement is to place the production well near the base of the pay zone. Development areas are selected according to various criteria including net continuous bitumen; top gas and water, lean zones; cap rock thickness; and surface constraints including proximity to the central processing facility.

In our study area, the base of the pay zone is the base of high porosity bitumen saturated-sandstone facies, located below the seismically-constrained youngest meander-belt deposit. Typically, petrophysical well logs show that porosity and bitumen saturation is highest at these depths; in the absence of vertical flow barriers and baffles, it is a sweet spot for well pair placement. However, the lack of lithologic contrast and resolution of seismic data limits the interpretation of depositional elements at these depths. The amalgamation of sandy meander-belt deposits makes correlations difficult and adds to the complexity of reservoir characterization. Mapping mudstone-filled abandoned channels and muddy IHS areas of the lower meander belt deposit(s) are critical to horizontal well pair placement. These impermeable elements block vertical steam chamber growth and limit depletion from the thick, overlying bitumen-saturated point bar deposits. Similarly, drilling and placing the wells inside these poor reservoir-quality depositional elements affect productivity or injectivity, leading to a partial loss of the drilled lateral length. Wireline well logs, core descriptions, and stratigraphic dip analysis are used to infer the distribution of channel elements in the underlying deposits (Fustic et al. 2007). This limited source of data incurs uncertainty in interpreting depositional elements and spatial distribution of reservoir vs. non-reservoir facies. 
Below the base of the meander-belt strata and above the sub-Cretaceous unconformity, the McMurray Formation is characterized by smaller upward fining fluvial channel deposits that are encased in finegrained deposits including floodplain, paleosol and lacustrine units. These smaller channels - less than $10 \mathrm{~m}$ thick and 100-150 m wide - are related to relatively localized paleodrainages that incised Devonian strata (Benyon et al., 2016). Imaging this amalgam of non-reservoir units - between the base of porosity and top of unconformity - is equally crucial to optimal well placement and field development planning.

Benchmark dataset and SWD simulations. Here we present the detailed procedure to provide the ground truth velocity model benchmark, SWD simulations, and the imaging workflow. The presented geological models represent the most likely interpretation of the reservoir, deemed the most useful and realistic for field development purposes. For optimal field development planning, we recommend performing sensitivity studies to evaluate the uncertainties in both deterministic and stochastic modeling, although such studies are beyond the scope of this paper.

The detailed geological model is conditioned to the well logs, which include sonic and density logs. Using the geological facies model, we assign different impedances to each lithology. This results in detailed subsurface velocity and density profiles that we use as the ground truth to evaluate the potentials of the SWD compared with the conventional drilling practices in SAGD developments.

The detailed and comprehensive modeling and simulation of the SWD data is not trivial. Researchers consistently improve modeling algorithms in consideration of deviations in the well, drill pipe friction, rate of penetration, and other complexities in drill string parameterization that generate a realistic SWD source signature (Ritto et al. 2009; Ghasemloonia et al. 2015; Auriol et al. 2020). Note that SWD data from the McMurray Formation are not available at this time. To show the potential benefits of SWD, we simulate data recordings by using the acoustic finite-difference modeling approach (José et al. 2002). We design a cross-well imaging scenario where two vertical wells are in-plane with the horizontal producer drilling operation. The geophones in the nearby vertical well record the vertical particle displacement.

Simulation of an SWD dataset requires detailed drillbit-rock interaction modeling. This interaction acts as an external force and generates significant elastic energy that propagates through the subsurface, which is ultimately detected by the geophones. In the interim, we use the approach recently introduced by Auriol et al. (2020) for drillbit-rock interaction modeling. In their methodology, they consider the axial motion of the drill string with negligible drill pipe friction, a roller cone bit, and a constant rate of penetration in the drilling process. They use wave equation modeling of the drill string dynamics and simulate the forces along the drill string. The WOB is estimated from this simulation workflow, which acts as an external source similar to seismic sources. However, the drillbit source signature is continuous and correlative, unlike impulsive surface seismic sources such as dynamite. The authors also show that the drillbit source signature can be estimated by using top-drive force and velocity measurements. In this paper, we merely use the drill string modeling approach for modeling the drillbit source signature, and the limitations in the drill string modeling do not pose any limitations in our proposed SWD imaging method.

We use the ground truth subsurface velocity and density profiles together with the simulated drillbit source signature to generate simulated SWD data. To deliver the SWD depth migrated image, we implement a pre-stack reverse time migration algorithm (Baysal et al. 1983; McMechan 1983; Whitmore 1983; Kazemi et al. 2018). The drillbit source signature and the background subsurface velocity are the inputs for the proposed SWD imaging method. We use the SMBD algorithm and estimate the drillbit source signature using the simulated data. Furthermore, we borrow the depth velocity model provided by surface seismic processing, as a background subsurface velocity, for SWD imaging.

Case A: Producer partially drilled in non-reservoir facies, across reservoir boundary. This case examines the downsides of placing a horizontal producer in a suboptimal location. The producer is placed 
near the base of the pay zone to maximize recovery, but is partially drilled into a mudstone-filled channel associated with the lower meander-belt deposit. The proximity of the mudstone-filled channel to the highly reflective Devonian Unconformity challenges the precise interpretation and estimation of the threedimensional distribution of this non-reservoir rock.

Figure-3 shows a cross-section that encounters a horizontal well pair. Different colors highlight the depositional elements of the reservoir. The log example alongside both injector and producer show typical GR log responses for common sedimentary rock types; cool colors (blue-green) correspond to high GR values whereas hot colors (yellow-orange-red) correspond to low GR values.

The length of the producer is $860 \mathrm{~m}$. Approximately the last $140 \mathrm{~m}$ of the lateral section is characterized by high GR values (>90 API), highlighting suboptimal well placement and drilling of non-reservoir facies (mudstone). The corresponding injector is drilled according to the producible length of the underlying producer well, and as such, is $140 \mathrm{~m}$ shorter than the designed length and pad average.

Figure-4A displays the production data for this well pair. The average monthly oil production is roughly $1,400 \mathrm{~m}^{3}$ with a cumulative steam oil ratio (cSOR) of $3.6 \mathrm{~m}^{3} / \mathrm{m}^{3}$. This well pair has a lower oil production rate and a higher cSOR compared to other well pairs in the same pad, which is attributable to the shorter producible length and the smaller drainage volume as a result of proximity to the reservoir boundary (mudstone-filled channel or edge of the meander belt). Table-1 compares the production data with other case studies; the data for the pad average is also included as the baseline to highlight the difference between superior and low performing cases.

Figure-5 shows the overlay of subsurface velocity profile and high-resolution SWD image corresponding to the cross-section represented in Figure-3. The mudstone boundary is remarkably well imaged with the proposed SWD imaging algorithm. To generate the SWD image, we numerically simulated 15 equally spaced drillbit sources in the vertical section of the production well and we considered a vertical well on the right-hand side of the cross-section. Hence, we recorded the numerically simulated pressure wavefields at the right-hand side vertical well. By doing so, we show that the subsurface image of cross well SWD data could efficiently reveal the mudstone/reservoir boundary. Accordingly, the high-resolution SWD image is a vital source of information for optimal well placement and avoidance of risky zones. In this case, where the horizontal producer reaches and penetrates the reservoir boundary, the optimal geosteering solution, in practice, is not steering the horizontal well above the non-reservoir zone. SWD interpretations provide improved images of the boundary in advance of well penetration (Figure-5), providing sufficient time to make a decision to steer the well to the sides or cease drilling altogether. In practice, this application saves rig time and minimizes drilling costs; if look-ahead technology is used to optimally place the well in reservoir facies, then the incremental increase in production (increasing production to pad average, for instance) would cover the costs of the SWD system.

Case B: Optimal drilling and well placement. This case presents the optimal well placement with little or no loss of producible length of the horizontal wells (Figure-6). The producer is placed near the base of porosity and both injector and producer are drilled in reservoir facies with good porosity and high bitumen saturation. The production performance of this well pair is well above the pad average and is one of the best well pairs in the pad (Figure-4B). The average monthly oil production is $3,600 \mathrm{~m}^{3}$ with a cSOR of $2.8 \mathrm{~m}^{3} / \mathrm{m}^{3}$ (Table-1).

It is important to highlight that the very last few meters $(20 \mathrm{~m})$ of the injector penetrates an element of the upper meander belt. This element is a separate, older unit not related to the modeled meander-belt deposit, with high IHS and mudstone facies proportions. As a result, the GR response near the end of this injector is characterized by high values, which correspond to non-reservoir facies. Again, this demonstrates the need for detailed reservoir characterization and precise interpretation of point bar elements, including the three-dimensional geometry and facies distribution prior to field development planning in SAGD settings. 
Case C: Producer is partially drilled in non-reservoir paleosols/basal shales. In this case, we discuss a scenario where portions of the horizontal producer are placed in non-reservoir rocks, below the targeted interval (Figure-7). Consider non-uniform 3D seismic resolution and a pad size of $1000 \times 1000 \mathrm{~m}^{2}$; typically, 10 vertical cored or logged stratigraphic wells are drilled in such pads. This leads to an average vertical well spacing (sampling) of 10 hectares/well. That is sufficient to map flat structures like the base meander-belt, but introduces significant uncertainty in 1) interpreting depositional elements and 2) estimating reservoir boundaries, as defined by the edge of meander belts.

As mentioned, optimal horizontal well placement in a SAGD setting necessitates placing the producer well as close as possible above the base of bitumen. A detailed map ( $<1 \mathrm{~m}$ uncertainty) of the highs and lows on the undulatory, sub-Cretaceous unconformity surface, facies variations, as well as basal water distribution is needed. In this example, because of inadequate vertical well sampling and low-resolution 3D seismic data near the base of the reservoir, the vertical position of the producer was suboptimally placed with approximately the first half of the producer drilled in mudstone and IHS. The GR log shows an average value of 70 API that corresponds to sandy and muddy IHS facies. This has significantly affected the production performance of the well pair. The average monthly oil production of this well pair is $2,100 \mathrm{~m}^{3}$ and $\mathrm{cSOR}$ is $4.1 \mathrm{~m}^{3} / \mathrm{m}^{3}$, which is quite poor compared to the pad average (Figure-4C). Yet, the production performance of this well pair is better than Case A, in which oil in place was lower due to proximity of the wells to the reservoir boundary, and the producer was partially drilled in mudstone.

The real-time SWD data potentially images the surface on top of non-reservoir basal shales, and it provides valuable information to support decision making, steering the well, and adjusting the landing point of the horizontal section.

Added value. There have been limited reports on the application of SWD in SAGD developments. The excessive costs of acquisition and interpretation need to be clearly justified in order to convince operators of its benefits. Several reports (e.g. Chemali 2011) clarify the benefits of SWD and its successful application in deep water and subsalt drilling environments. Improvements in drillbit behavior estimation using surface data (Auriol et al. 2020) eliminate the need for near-bit sensors, so the incremental cost of SWD is the cost of the surface geophone array for surface measurement or distributed acoustic sensing (DAS)/geophone placement in adjacent wells for interwell imaging. A discussion of missed or wasted resources during SAGD developments, considering both the cost of data acquisition and time spent on design and data interpretation, is not available at this time. In our case studies, we presented certain environments where look-ahead-of-the-bit information could drastically improve SAGD well placement, and ultimately, well deliverability. The production performance of adjacent well pairs shows the added value of optimal well placement and the potentials of SWD data.

A key design criterion in SAGD well placement is the target depth of the producer's horizontal track (e.g. Kumar and Deutsch 2010; Illfelder et al. 2011). Generally, horizontal wells are drilled using sparse vertical well sampling and surface seismic data. These sources of data have quite large uncertainty near the base of the pay zone, and as a result, laterals may not be optimally placed with regards to target petrophysical properties (Case C), and in some cases, even miss the desired target altogether (Case A). SWD can help to reduce this uncertainty by providing reflective information in real-time. Operators can update subsurface images and lessen the risks while the well is being drilled into the target zone.

Ahead-of-the-bit information helps geosteering engineers to mitigate the risks of drilling in unwanted zones without disturbing drilling operations. It provides indications of reflecting horizons/rocks and helps to detect non-reservoir facies. This supports both drilling and well completion design decisions. Aheadof-the-bit information is highly valuable to optimize casing landing point for horizontal SAGD wells placement. Besides, the detailed and high-quality rock type information is invaluable to optimize well 
completion design (e.g., placement of flow control devices) and maximize production performance (Nejadi et al. 2018).

Figure- 8 shows a seismic depth section of the meander belt in the study area. As discussed and illustrated in different case studies, in the area used for this study, the horizontal well pairs are often placed between the base of the upper meander-belt deposit and top Devonian strata. Seismic profiles at these depths show non-uniform resolution rendering geological interpretations, yielding a challenging task. Due to the strong reflectance at the contact between poorly consolidated sediments of the McMurray Formation and competent underlying Devonian limestones, the surface seismic resolution is relatively poor up to $10 \mathrm{~m}$ above the unconformity (Gray et al. 2015).

In the case of non-challenging SAGD development areas with flat structures near the base, seismic-whiledrilling information will provide detailed images of the internal elements of the reservoir deposit, resulting in reduced uncertainties in characterization. The operator may use detailed geological models to fine-tune well-pair orientations in adjacent wells or future pads. For example, orienting wells perpendicular to point bar accretion surfaces has been shown to maximize productivity (Su et al. 2017).

\section{Multi-Well Pad Drilling}

Multi-well pad drilling reduces both time and costs by allowing for shared construction, equipment, and facilities, reducing the surface footprint while minimizing rig moving expenses (Abramov et al. 2018). It further provides an opportunity for continuous process improvement. In this paper, we propose improvements to well placement strategies that can enhance production efficiency in the context of multiwell pad drilling. This approach fine-tunes the placement of horizontal wells with the help of drilling and subsurface data obtained in real-time while drilling previous laterals. A result may be that the sequence of lateral drilling may be modified as data is collected through the batch drilling process.

The sequence starts with drilling the first lateral in the best-characterized, less uncertain part of the pad that inherently implements the best knowledge of the subsurface. Subsurface images are updated while drilling the horizontal wells. The seismic-while-drilling information reduces uncertainties and updates the current understanding of the presence, scale, and continuity of low-quality facies. This approach follows the idea of real-time well placement and completion design, where the next horizontal well in the drilling sequence is specified according to the updated risks and uncertainties (Güyagüler and Horne 2004), instead of a pre-defined order using a priori knowledge. The selection criteria and placement of the next laterals are modified in real-time using the lessons learned from the previous drilling. Our proposed workflow challenges the practice of merely skidding the rig over a few meters and drilling the next lateral in a pre-designed manner that solely relies on sparse vertical well sampling and three-dimensional seismic with non-uniform resolution in the depths of lateral placement.

\section{Discussion}

The proposed SWD imaging consists of two parts. The first part is the drillbit source signature estimation algorithm, and the second part is the pre-stack imaging methodology. Compared to the pre-stack depth imaging, the computational cost of estimating the dill bit source signature is negligible. The computational cost of pre-stack depth imaging depends on the number of SWD shot gathers, the number of frequency realizations, and the subsurface grid points in the imaging region (Mulder and Plessix 2004; Kazemi and Sacchi 2015). To compute the computational intensity of this approach, consider the number of grid points in each direction as $n$, the number of grid points in 2D is $O\left(n^{2}\right)$. The order of complexity of pre-stack depth migration for this 2D acquisition system, with $n_{s}$ shot points and $n_{f}$ frequency realizations, is $O\left(n_{f} n^{3}\right)+$ $O\left(n_{f} n_{s} n^{2} \log n\right)$. Hence, to provide a near real-time SWD image, the computational complexity of imaging must be smaller or equal to the drilling time for the $n$, number of grid points in the subsurface area. 
Accordingly, depending on the drilling practices, the number of grid points in the imaging area could be adjusted to achieve near real-time SWD imaging.

Here, our focus is on acoustic modeling and imaging. However, our methodology can be extended to elastic modeling and imaging as well. The axial and rotational motions of the drillbit acting on the rock generates elastic energy, and this elastic energy can be recorded by multicomponent receivers and used in the elastic imaging process.

The presented algorithm estimates the drillbit source signature efficiently regardless of the quality of the pilot trace. This is especially important when dealing with PDC bit drilling. PDC bits shear the rocks while drilling and unless drilled in hard rocks or when the PDC bit is damaged, it produces weak axial motion (P-wave) along the drill string (Meehan et al. 1998). Hence, the signal recorded by the accelerometer on top-drive is not strong enough. Accordingly, the PDC bit does not provide useful pilot trace or surface measurements while drilling. On the other hand, by eliminating the need for recording the pilot trace, the methodology measures the elastic energy generated by the PDC bit in nearby wells and provides SWD images. Moreover, by having access to an accurate drillbit source signature, instead of building the RVSP gathers, Kazemi et al. (2018) used the estimated drillbit source signature, along with the background subsurface velocity provided by kinematic analysis of the surface seismic data, to deliver pre-stack depth migrated images. As the new algorithm uses pre-stack imaging methodology, there is a possibility for providing angle gathers. The angle gathers can be inverted for subsurface rock properties. Furthermore, within the new framework, full-waveform inversion of the SWD data is achievable. Full-waveform inversion of SWD data gives the high-resolution subsurface velocity or physical parameters of the rocks around and ahead of the drillbit (Kazemi et al. 2020). This potentially aids in detecting shallow gas zones ahead-of-the-bit. The rock properties provided by full-waveform inversion of SWD data or by inverting the angle gathers when used in conjunction with drilling parameters, MWD data, and cuttings analysis gives an estimate of the pore pressure at the bit (Meehan et al. 1998).

\section{Conclusions}

This paper demonstrates the value of look-ahead-of-the-bit information for multi-well pad drilling in SAGD settings. We use a novel SWD imaging algorithm that provides high-resolution subsurface images. Imaging ahead of the bit provides an opportunity to adjust the drilling parameters, update the well trajectory and improve 1) well placement and 2) drilling performance. The approach consists of estimating the drillbit source signature and using it as an input to the SWD imaging algorithm. Later on, we use these images to update reservoir models and improve well placement. Implementation of SWD information in the context of SAGD well pad drilling in the presence of high geological uncertainty demonstrates reasonable improvement in optimal well placement. We show that the subsurface image of cross-well SWD data over the McMurray Formation could efficiently reveal the boundary between non-reservoir mudstone and reservoir sandstone. Accordingly, the high-resolution SWD image provide a reliable tool for adapting new drilling scenarios, optimally placing wells, and avoiding risky zones.

Application of SWD information potentially addresses the problem inherent in horizontal producer placement and minimizes risks of drilling in non-reservoir facies; it implements an improved image of the subsurface and reduces the uncertainties in estimating reservoir size, delineating reservoir boundaries, and predicting formation properties. The presented case studies show the potential for ahead-of-the-bit information in challenging and heterogenous SAGD systems and highlights the incremental increase in well pair bitumen production performance. In addition to improved well placement, the near-real-time updated subsurface images may provide sufficient time to fine-tune downhole well completion designs.

\section{Nomencluture}

Symbols 


\begin{tabular}{|c|c|c|}
\hline$\delta$ & $=$ & Dirac delta function \\
\hline$\epsilon$ & $=$ & Small number in Huber norm for approximation the $\mathrm{L}_{1}$ norm \\
\hline$\omega$ & $=$ & Angular frequency \\
\hline$\lambda$ & $=$ & Regularization parameter \\
\hline$\nabla^{2}$ & $=$ & Laplacian operator \\
\hline d & $=$ & Seismic data \\
\hline $\mathbf{e}$ & $=$ & Noise term in SMBD \\
\hline $\mathrm{f}$ & $=$ & Seismic source function \\
\hline $\mathbf{m}$ & $=$ & Subsurface image \\
\hline $\mathrm{n}$ & $=$ & Number of grid points \\
\hline $\mathbf{n}$ & $=$ & Noise in the data \\
\hline $\mathbf{r}$ & $=$ & Reflectivity \\
\hline $\mathbf{s}$ & $=$ & Slowness \\
\hline $\mathbf{x}$ & $=$ & Spatial position \\
\hline $\mathbf{y}$ & $=$ & Concatenation of the reflectivity series in all of the channels \\
\hline $\mathbf{A}$ & $=$ & Channels combination matrix for SMBD \\
\hline D & $=$ & Convolution matrix of seismic data, $\mathbf{d}$ \\
\hline $\mathbf{F}$ & $=$ & Toeplitz matrix built from the drillbit source signature time series \\
\hline G & $=$ & Green's function \\
\hline $\mathrm{J}$ & $=$ & Maximum number of channels per shot gather \\
\hline $\mathbf{N}$ & $=$ & Convolution matrix of noise \\
\hline $\mathrm{P}$ & $=$ & Pressure wavefield \\
\hline \multicolumn{3}{|c|}{ Subscripts } \\
\hline$f$ & $=$ & Frequency realization \\
\hline$i$ & $=$ & Channel index \\
\hline$j$ & $=$ & Channel index \\
\hline$p$ & $=$ & Channel index \\
\hline$q$ & $=$ & Channel index \\
\hline$s$ & $=$ & Shot points \\
\hline \multicolumn{3}{|c|}{ Superscripts } \\
\hline $\mathrm{T}$ & $=$ & Transpose \\
\hline * & $=$ & Conjugate transpose \\
\hline
\end{tabular}

\section{Acknowledgements}

The authors would like to acknowledge the University of Calgary's Canada First Research Excellence Fund (CFREF) program on unconventional resources for funding support and ConocoPhillips Canada for allowing use of the Surmont geomodel. PETREL software is provided by Schlumberger. 


\section{References}

Abramov, A.V., Bikbulatov, R.V., Kolesnik, I.Yu., Vinokurov, A.N., Mukhametshin, V.Kh. 2018. Boosting economic efficiency of pads drilling projects. A comprehensive study of wells groupings and localization of the global maximum, Journal of Petroleum Science and Engineering, v. 165, p. 212-222.

Auriol, J., Kazemi, N., Shor, R.J., Innanen, K.A., and Gates, I.D., 2020. A Sensing and Computational Framework for Estimating the Seismic Velocities of Rocks Interacting with the Drill bit, IEEE Trans. Geosci. Remote Sens., v. 58, no 5, doi:10.1109/TGRS.2019.2950257.

Baysal, E., Kosloff, D.D., Sherwood, J.W.C., 1983. Reverse time migration: Geophysics, v. 48, p. 1514-1524.

Benyon, C., Leier, A.L., Leckie, D.A., Hubbard, S.M., Gehrels, G., 2016, Sandstone provenance and insights into the paleogeography of the McMurray Formation from detrital zircon geochronology, Athabasca Oil Sands, Canada: AAPG Bulletin, v. 100, p. 269-287.

Butler, R.M., 1991. Thermal Recovery of Oil and Bitumen, Englewood Cliffs, New Jersey: Prentice Hall.

Butler, R.M. 1982. Method for continuously producing viscous hydrocarbons by gravity drainage while injecting heated fluids. US Patent 4344485 A.

Chapman, C., 2004. Fundamentals of seismic wave propagation, Cambridge university press.

Chemali, R. 2011. Advanced Geosteering for Optimal Exploitation of Hydrocarbon Reserves. Presentation for Society of Petroleum Engineers Distinguished Lecturer Program.

Dowell, I., Mills, A., Ridgway, M., Lora, M., 2006. Chapter 15 - Drilling-Data Acquisition. In Robert F. Mitchell (ed.). Petroleum Engineering Handbook. II - Drilling Engineering. Society of Petroleum Engineers. p. 647-685.

Durkin, P.R., Boyd R.L., Hubbard S.M., Shultz A.W., Blum M., 2017. Three-dimensional reconstruction of meander-belt evolution, Cretaceous McMurray Formation, Alberta Foreland Basin, Canada. Journal of Sedimentary Research v. 87, no. 10, p. $1075-1099$.

Fustic, M., Spencer, R., Hubbard, S., Bennett, B. and Larter, S., 2007. Dipmeter Application in Canadian Oil Sands Development - Evolution from Predicting Potential Block Slides to 3D Geological Interpretation and Modelling. AAPG and AAPG European Region Conference, November 18-21, Athens, Greece.

Ghasemloonia, A., Rideout, D.G., Butt, S.D., 2015. A review of drillstring vibration modeling and suppression methods. J. Petrol. Sci. Eng. v. 131, p. 150-164.

Gray, D., Day, S., Schapper, S., 2015. Rock physics driven seismic data processing for the Athabasca oil sands, Northeastern Alberta. CSEG Recorder March, p. 32-40.

Güyagüler, B., and Horne, R. N. 2004. Uncertainty Assessment of Well-Placement Optimization. Society of Petroleum Engineers. V. 7, no. 1. doi:10.2118/87663-PA

Hardage, B.A., 1985. Vertical seismic profiling, The Leading Edge, v. 4, no. 11.

Hartkamp-Bakker C.A., Donselaar M.E. 1993. Permeability patterns in point bar deposits: Tertiary Loranca Basin, central Spain, in the geological modelling of hydrocarbon reservoirs and outcrop analogs, Flint S.S., Bryant I.D. (eds), Int. Association of Sedimentologists Special Publication, IAS SP15, 157-168.

Hein, F.J., Dolby, G., Fairgrieve, B., 2013. A regional geologic framework for the Athabasca oil sands, northeastern Alberta, Canada. In: Hein, F.J., Leckie, D., Larter, S., Suter, J.R. (Eds.), Heavy-oil and Oil-sand Petroleum Systems in Alberta and beyond. American Association of Petroleum Geologists Studies in Geology vol. 64, pp. 207-250.

Horner, S.C., Hubbard, S.M., Martin, H.K., Hagstrom, C., and Leckie, D.A., 2019. The impact of Aptian glacio-eustacy on the stratigraphic architecture of the Athabasca Oil Sands, Alberta, Canada: Sedimentology, doi: 10.1111/sed.12545.

Hubbard, S.M., Smith, D.G., Nielsen, H., Leckie, D.A., Fustic, M., Spencer, R.J., and Bloom, L., 2011. Seismic geomorphology and sedimentology of a tidally influenced river deposit, Lower Cretaceous Athabasca Oil Sands, Alberta, Canada: AAPG Bulletin, v. 95, p. 1123-1145.

Illfelder, H., Forbes, E., McElhinney, G., Rennie, A., Schaepsmeyer, H., Krawchuk, A., 2011. A Systematic Approach for Wellbore Drilling and Placement of SAGD Well Pairs and Infill Wells. WHOC paper 11-503, presented at the World Heavy Oil Congress, Edmonton, Alberta, Canada, March 14-17.

José, M. C., Gérard, C. H., ten Kroode, A. P. E., 2002. Seismic modeling, Geophysics, v. 67, no. 4, 1304-1325, doi:10.1190/1.1500393.

Journel, A.G., 2002. Combining Knowledge from Diverse Sources: An Alternative to Traditional Data Independence Hypotheses. Mathematical Geology, v.34, p. 573-596.

Justice, J.H., Vassiliou, A.A., Singh, S., Logel, J.D., Hansen, P.A., Hall, B.R., Hutt, P.R., and Solanki, J.J., 1989. Acoustic Tomography for Monitoring Enhanced Oil Recovery, Leading Edge, 10:12.

Kazemi, N., Sacchi, M.D., 2014. Sparse multichannel blind deconvolution: Geophysics, v.79, no. 5, V143-V152, doi: 10.1190/geo20130465.1.

Kazemi, N., Sacchi, M.D., 2015. Block row recursive least-squares migration: Geophysics, v.80, no. 5, A95-A101, doi.org/10.1190/geo20150070.1 .

Kazemi, N., Shor, R., Innanen, K., 2018. Illumination compensation with seismic-while-drilling plus surface seismic imaging. In proceedings: 80th EAGE Conf. Exhibit, Copenhagen, Denmark, 11-14 June.

Kazemi, N., Auriol, J., Innanen, K., Shor, R., Gates, I., 2020. Successive Full-Waveform Inversion of Surface Seismic and Seismic-WhileDrilling Datasets without Low Frequencies: Accepted for presentation, 82nd EAGE Conf. Exhibit, Amesterdam, The Netherlands, 811- December. 
Kumar, A., Deutsch, C.V., 2010. Optimal Vertical Placement of Well Pairs in SAGD. CCG Report 2010.

Martinius, A.W., Fustic, M., Garner, D.L., Jablonski, B.V.J., Strobl, R.S., MacEachern, J.A., Dashtgard, S.E., 2017. Reservoir characterization and multiscale heterogeneity modeling of inclined heterolithic strata for bitumen-production forecasting, McMurray Formation, Corner, Alberta, Canada: Marine and Petroleum Geology, v. 82, p. 336-361.

McMechan, G.A., 1983. Migration by extrapolation of time-dependent boundary values: Geophysical Prospecting, v. 31, p. 413-420.

Meehan, R. J., Nutt, L., Dutta, N., Menzies, J., 1998. Drill Bit Seismic: A Drilling Optimization Tool. Society of Petroleum Engineers. doi:10.2118/39312-MS.

Mulder, W A., and Plessix, R-E., 2004. A comparison between one-way and two-way wave-equation migration: Geophysics, v. 69, no. 6, 1491-1504.

Musial, G., Reynaud, J.-Y., Gingras, M.K., Fenies, H., Labourdette, R., Parize, O., 2012. Sub- surface and outcrop characterization of large tidally influenced point bars of the Cre- taceous McMurray Formation (Alberta, Canada). Sedimentary Geology $279,156-172$.

Nejadi, S., Curkan, J.A., Durkin, P.R., Hubbard, S.M., Gates, I.D. 2019. Integrated Reservoir Characterization and Multiscale Heterogeneity Modeling of Stacked Meander-belt Deposits, Lower Cretaceous McMurray Formation, Alberta. In proceedings: $4^{\text {th }}$ EAGE Petroleum Geostatistics Conference, Florence, Italy, 2-6 September.

Nejadi, S., Hubbard, S.M., Shor, R.J., Gates, I.D., Wang, J. 2018. Optimization of Placement of Flow Control Devices under Geological Uncertainty in Steam Assisted Gravity Drainage. Presented at the SPE Thermal Well Integrity and Design Symposium, Banff, Alberta, Canada, 27-29 November.

Poletto, F., Miranda, F., 2004. Seismic while drilling: Fundamentals of drill-bit seismic for exploration, volume 35, Elsevier.

Rector, J. W., Marion B. P., 1991. The use of drill-bit energy as a downhole seismic source, Geophysics, v 56, no. 5, p. 628-634.

Richardson J.G., Harris D.G., Rossen R.H., Van Hee G., 1978. The Effect of Small, Discontinuous Shales on Oil Recovery, Journal of Petroleum Technology, v.20, p.1531-1537.

Ritto, T.G., Soize, C., Sampaio, R., 2009. Non-linear dynamics of a drill-string with uncertain model of the bit-rock interaction. Int J Non Linear Mech. v. 44, no. 8, p. 865-76. doi:10.1016/j.ijnonlinmec.2009.06.003.

Strobl, R.S., Wightman, D.M., Muwais, W.K., Cotterill, D.K., and Yuan, L.P., 1997. Geological modelling of McMurray Formation reservoirs based on outcrop and subsurface analogues, in Pemberton, S.G., and James, D.P., eds., Petroleum Geology of the Cretaceous Mannville Group, Western Canada: Canadian Society of Petroleum Geologists, Memoir 18, p. 292-311.

Su, Y., Wang, J., Gates, I.D., 2017. SAGD Pad performance in a point bar deposit with a thick sandy base. Journal of Petroleum Science and Engineering, v. 154, p. 442-456.

Thiel, M., Omeragic, D., Seydoux, J., 2019. Enhancing the Look-Ahead-of-the-Bit Capabilities of Deep-Directional Resistivity Measurements While Drilling. Society of Petrophysicists and Well-Log Analysts. SPWLA-2019-Z.

Thomas, R.G., Smith, D.G., Wood, J.M., Visser, J., Calverley-Range, E.A., Koster E.H., 1987. Inclined heterolithic stratification terminology, description, interpretation and significance: Sedimentary Geology, v. 53, p. 123-179.

Upchurch, E. R., Viandante, M. G., Saleem, S., \& Russell, K. 2016. Geo-Stopping with Deep-Directional-Resistivity Logging-WhileDrilling: A New Method for Wellbore Placement with Below-the-Bit Resistivity Mapping. Society of Petroleum Engineers. doi:10.2118/173169-PA

Washbourne, J., Rector, James, W., Bube, K.P., 2002. Multi-crosswell profile 3D imaging and method. US Patent 6,388,947.

Whitmore, N.D., 1983. Iterative depth migration by backward time propagation: 53rd Annual International Meeting, SEG, Expanded Abstracts, 382-385.

Yan, N., Mountney, N.P., Colombera, L., and Dorrell, R.M., 2017. A 3D forward stratigraphic model of fluvial meander-bend evolution for prediction of point bar lithofacies architecture: Computers \& Geosciences, v. 105, p. 65-80.

Zhang, W., Youn, S., and Doan, Q., 2007. Understanding reservoir architectures and steam chamber growth at Christina Lake, Alberta, by using 4D seismic and crosswell seismic imaging. SPE Reservoir Evaluation and Engineering v. 10, no. 5, p. 446-452.

\section{SI Metric Conversion Factors}

$\begin{array}{lllll}\mathrm{ft} \times 3.048^{*} & \mathrm{E}-01 & = & \mathrm{m} \\ \mathrm{ft}^{3} \times 2.832 & \mathrm{E}-02 & = & \mathrm{m}^{3} \\ \mathrm{bbl} \times 1.589 & \mathrm{E}-01 & = & \mathrm{m}^{3} \\ \mathrm{ft} / \mathrm{s} & \times 3.048^{*} & \mathrm{E}-01 & = & \mathrm{m} / \mathrm{s}\end{array}$

*Conversion factor is exact. 


\section{Figures and Tables}
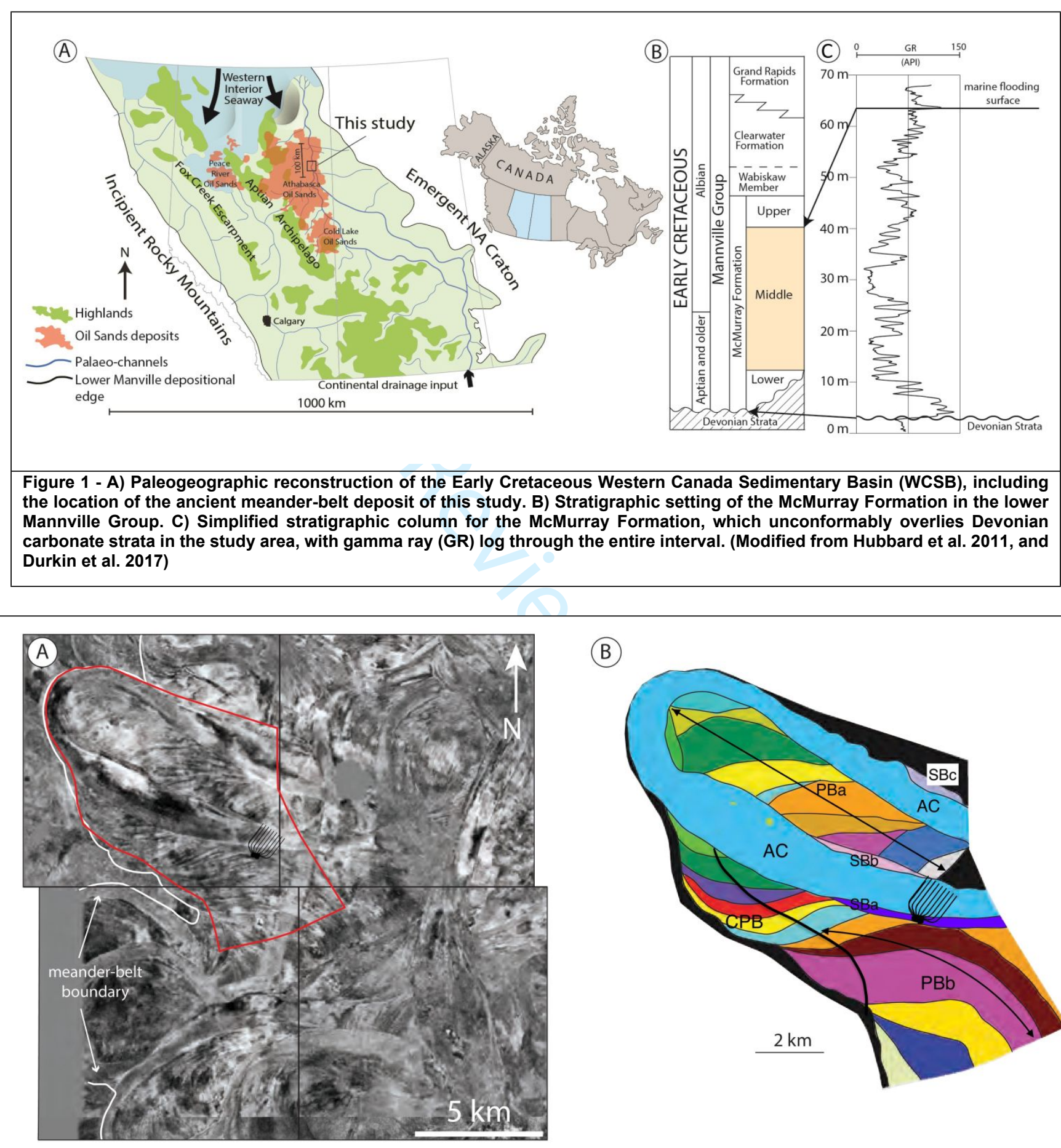

(B)

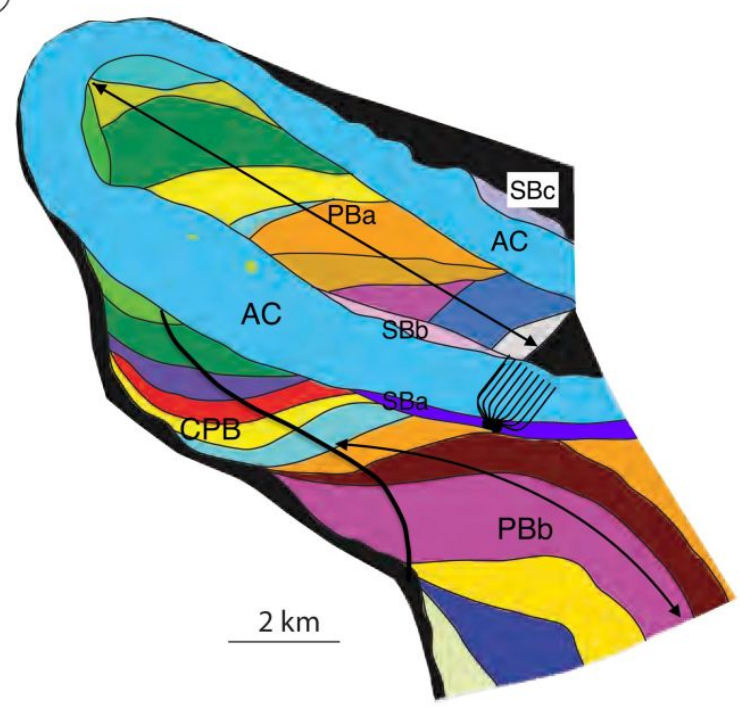

Legend:

UModel Boundary

Figure 2 - A) 3D seismic-amplitude stratal slice and B) zone model of the seismically constrained youngest meander-belt deposit in the study area (Point bar (PBa and PBb), counter-point bar (CPB), side bars (SBa, SBb, and SBc), and abandoned channel (AC)). (Modified from Durkin et al. 2017) 


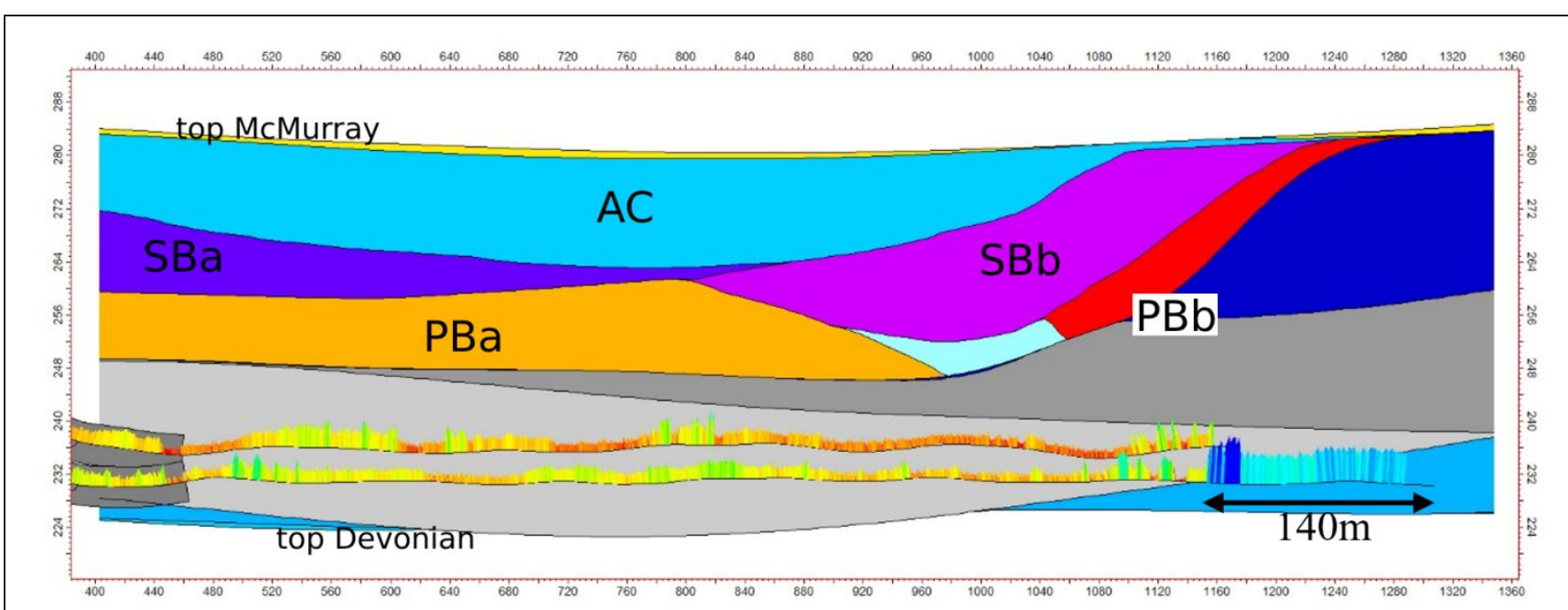

Figure 3 - Vertical reservoir cross section along Case A well pair (injector above producer). Different colors define different zones (i.e., roughly equivalent to depositonal elements) in the model, with GR logs shown along the laterals. The horizontal scale is $1: 2800$, and the vertical exaggeration is 4.5 .

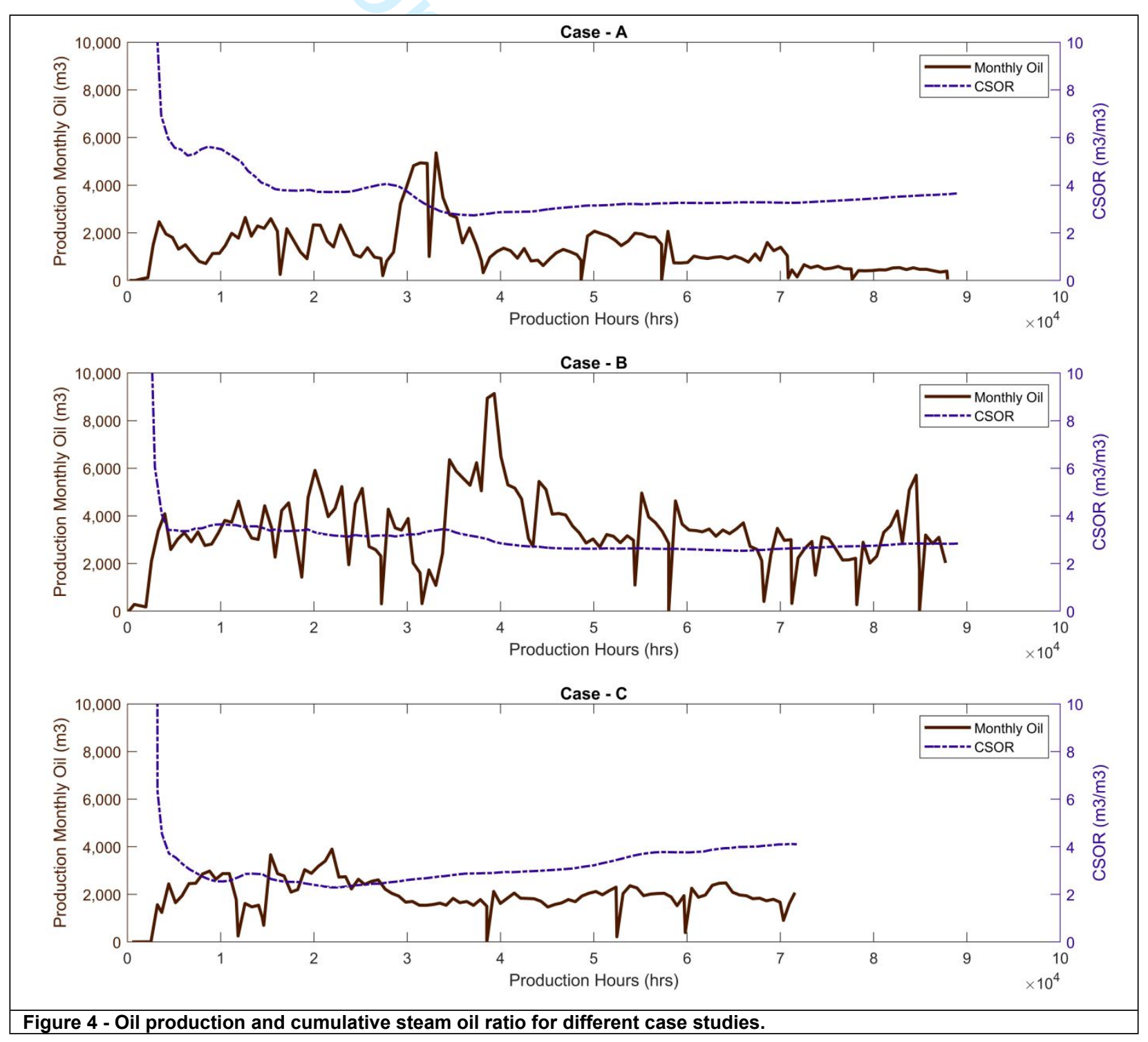




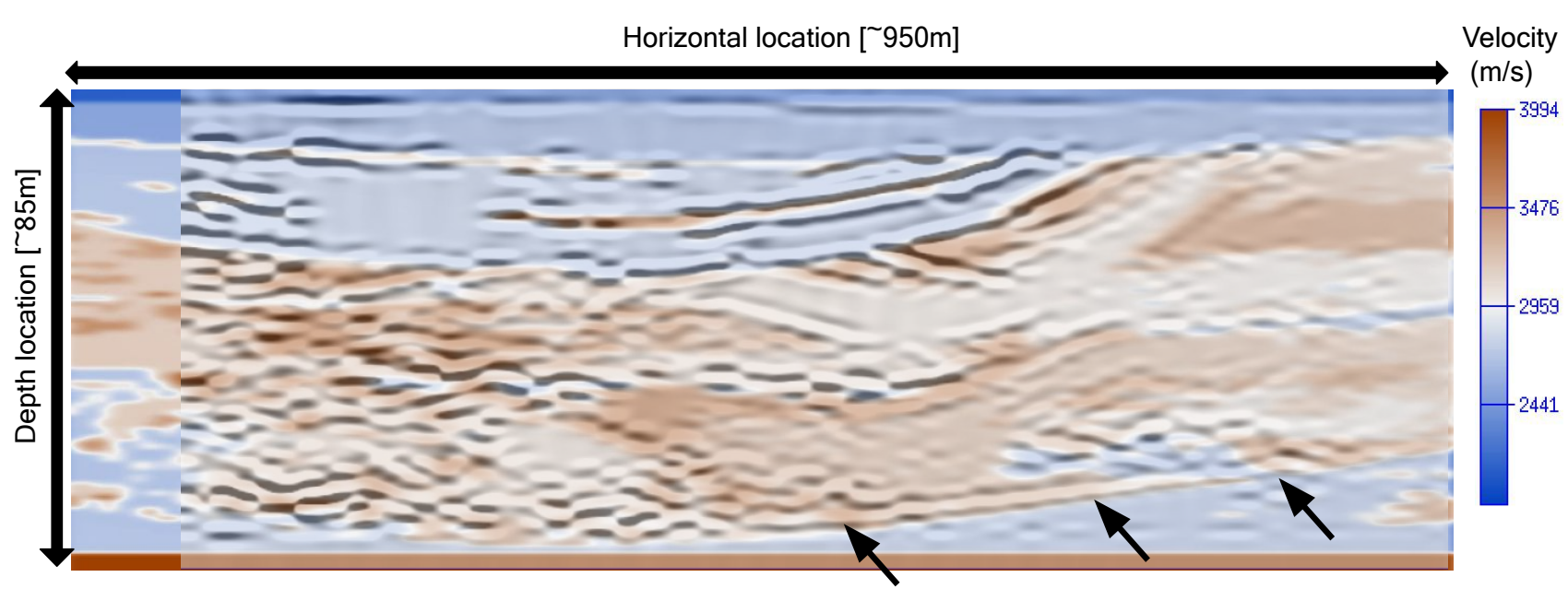

Figure 5 - Overlay of subsurface velocity profile and high-resolution SWD image corresponding to the cross-section represented in Figure-3. Black arrows highlight the boundary between reservoir-quality facies and mudstone.
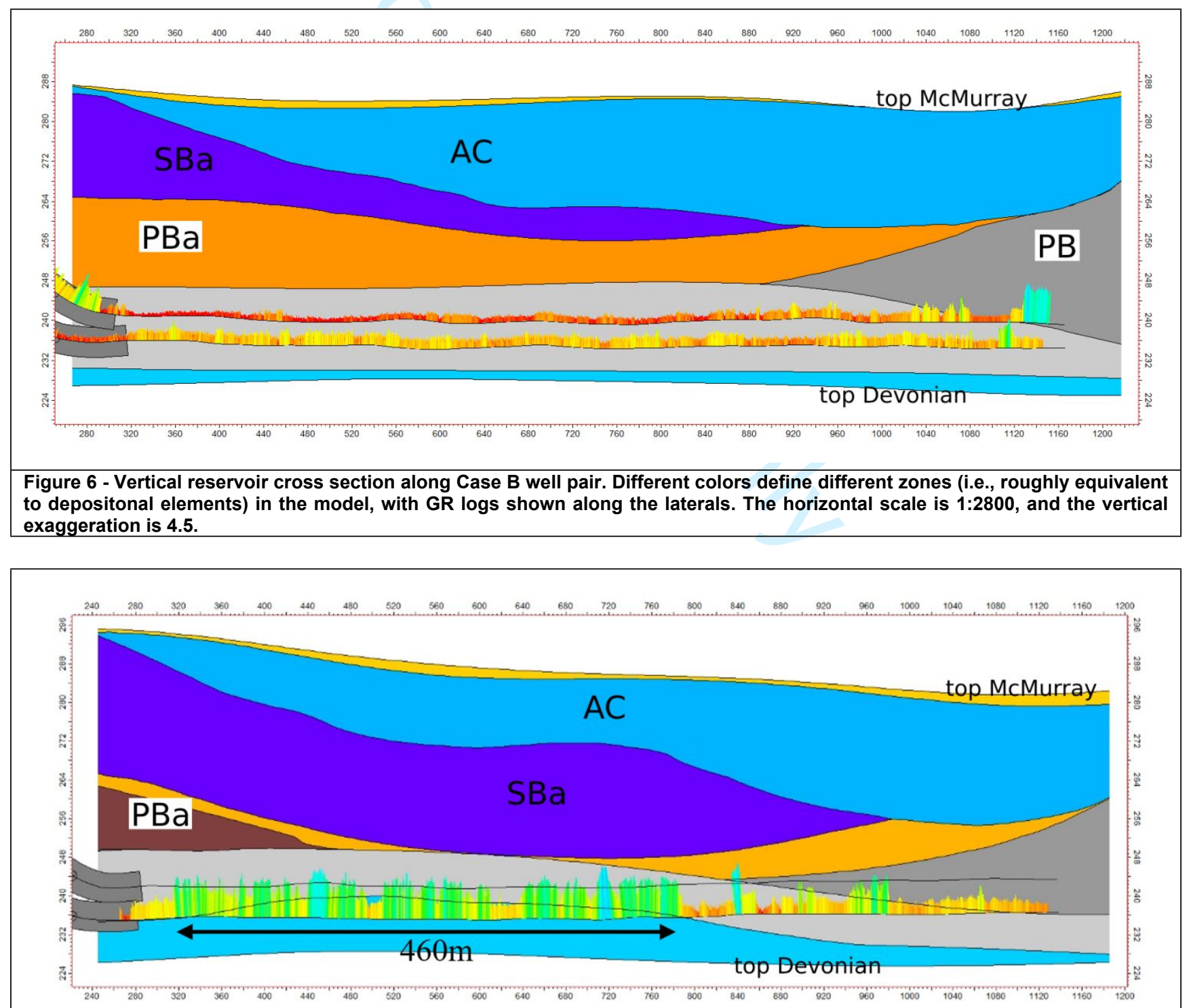

Figure 7 - Vertical reservoir cross section along Case C well pair. Different colors define different zones (i.e., roughly equivalent 
to depositonal elements) in the model, with GR logs shown along the laterals. The horizontal scale is 1:2800, and the vertical exaggeration is 4.5 .
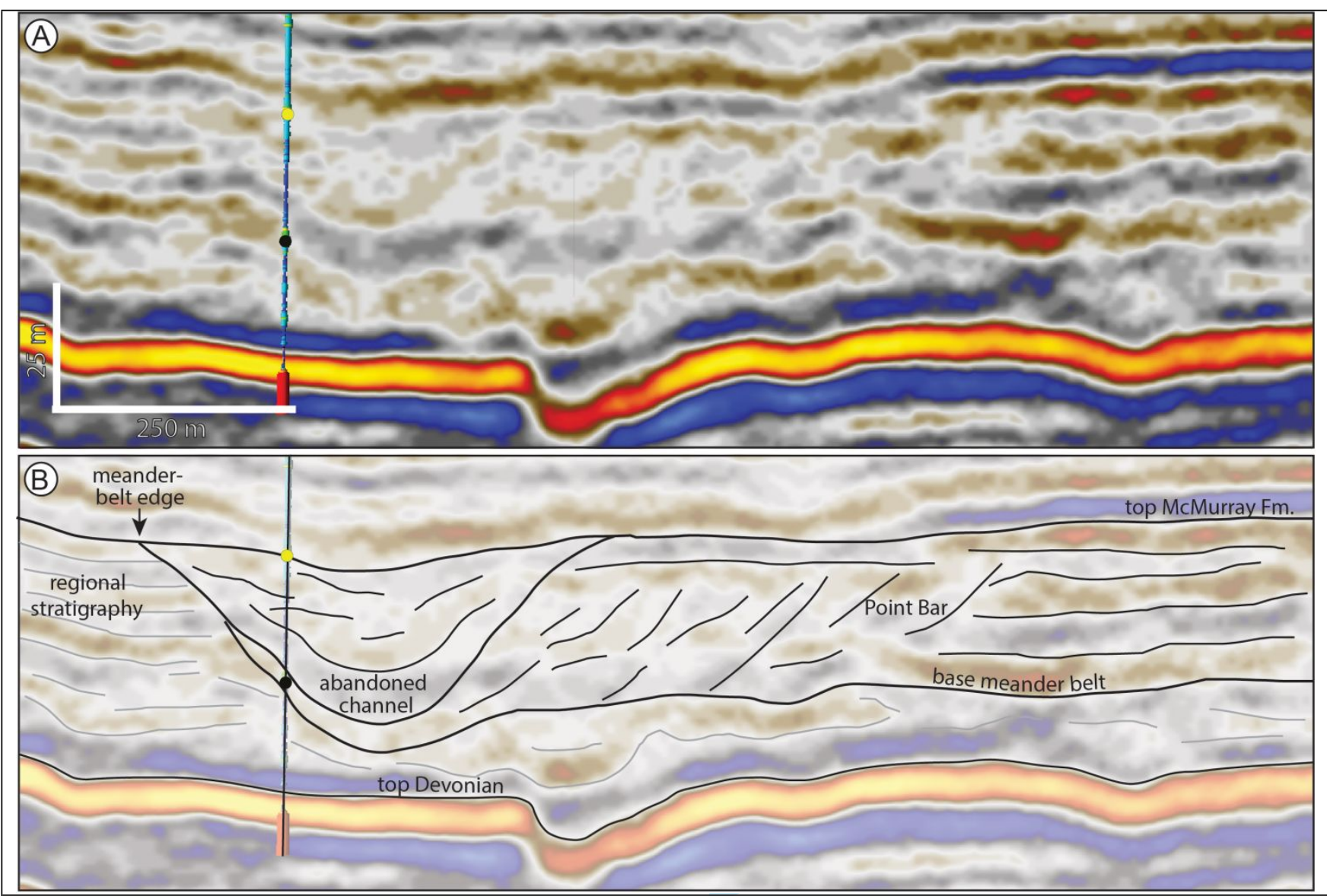

Figure 8 - A) Seismic-depth cross section of the McMurray Formation in the study area. B) Line trace showing the elements of meander-belt deposits at different stratigraphic levels. 3D seismic resolution is relatively poor up to $10 \mathrm{~m}$ above the unconformity.

(Modified from Durkin et al. 2017)

Table 1 - Well data, average monthly oil production, and cumulative steam oil ratio for different case studies compared with the pad average.

\begin{tabular}{|c|c|c|c|c|}
\hline Case & Producer Length & Injector Length $(\mathrm{m})$ & Monthly Oil $\left(\mathrm{m}^{3}\right)$ & $\mathrm{CSOR}\left(\mathrm{m}^{3} / \mathrm{m}^{3}\right)$ \\
\hline A & $850(140 \mathrm{~m}$ Mudstone $)$ & 710 & 1,400 & 3.6 \\
\hline B & 860 & 860 & 3,600 & 2.8 \\
\hline C & $840(463 \mathrm{~m}$ IHS $)$ & 840 & 2,100 & 4.1 \\
\hline Pad Average & 850 & 850 & 2,700 & 3.4 \\
\hline
\end{tabular}




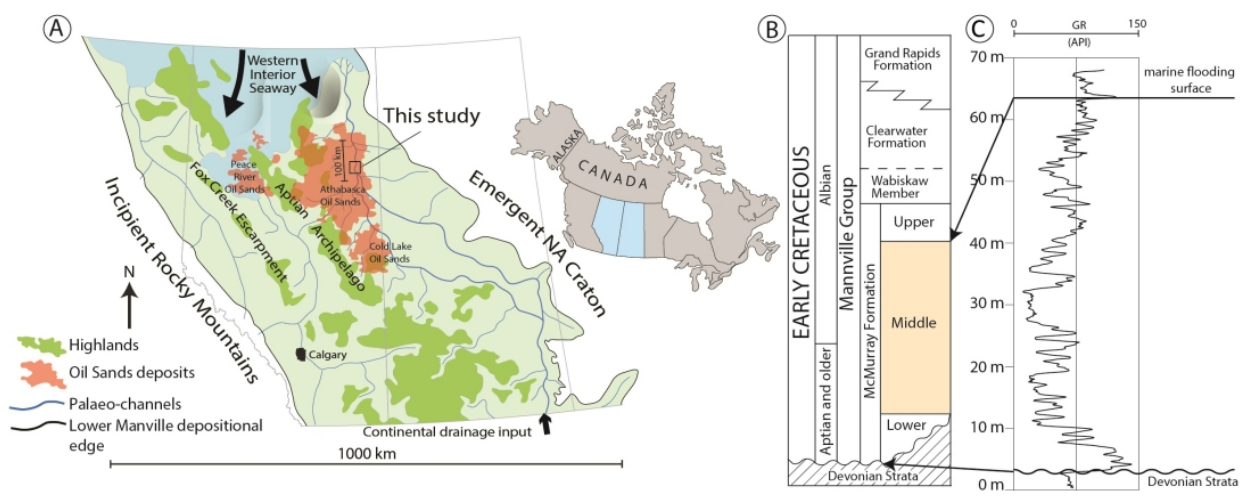

Figure 1 - A) Paleogeographic reconstruction of the Early Cretaceous Western Canada Sedimentary Basin (WCSB), including the location of the ancient meander-belt deposit of this study. B) Stratigraphic setting of the McMurray Formation in the lower Mannville Group. C) Simplified stratigraphic column for the McMurray Formation, which unconformably overlies Devonian carbonate strata in the study area, with gamma ray (GR) log through the entire interval. (Modified from Hubbard et al. 2011, and Durkin et al. 2017) 


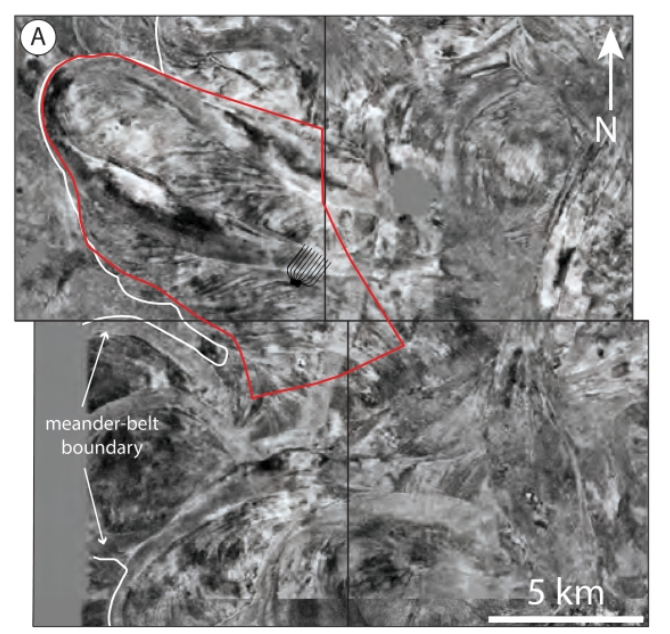

(B)

Figure 2 - A) 3D seismic-amplitude stratal slice and B) zone model of the seismically constrained youngest meander-belt deposit in the study area (Point bar (PBa and PBb), counter-point bar (CPB), side bars (SBa, $\mathrm{SBb}$, and SBC), and abandoned channel (AC)). (Modified from Durkin et al. 2017) 


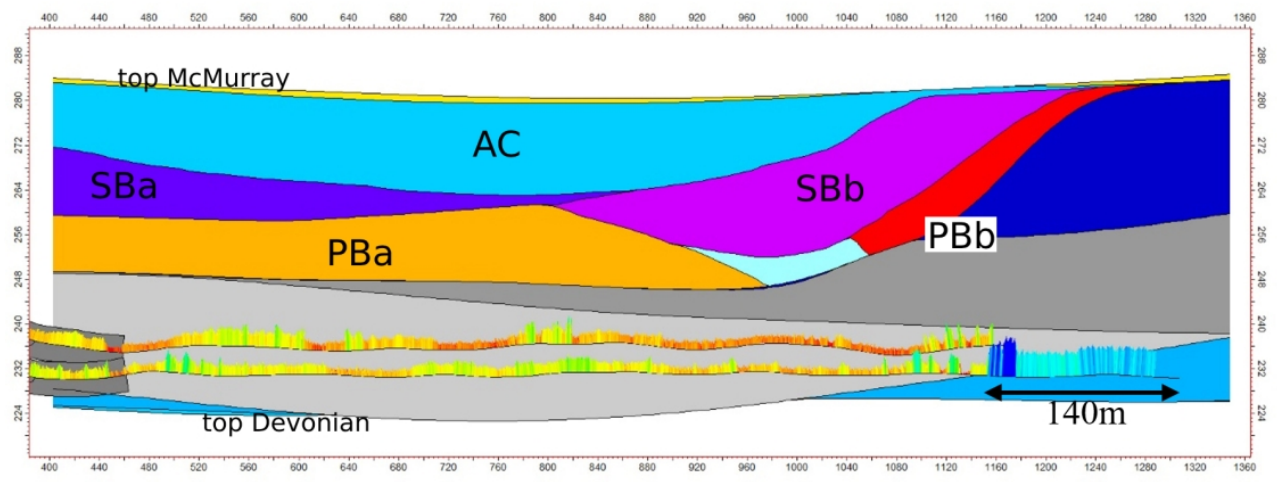

Figure 3 - Vertical reservoir cross section along Case A well pair (injector above producer). Different colors define different zones (i.e., roughly equivalent to depositonal elements) in the model, with GR logs shown along the laterals. The horizontal scale is $1: 2800$, and the vertical exaggeration is 4.5. 

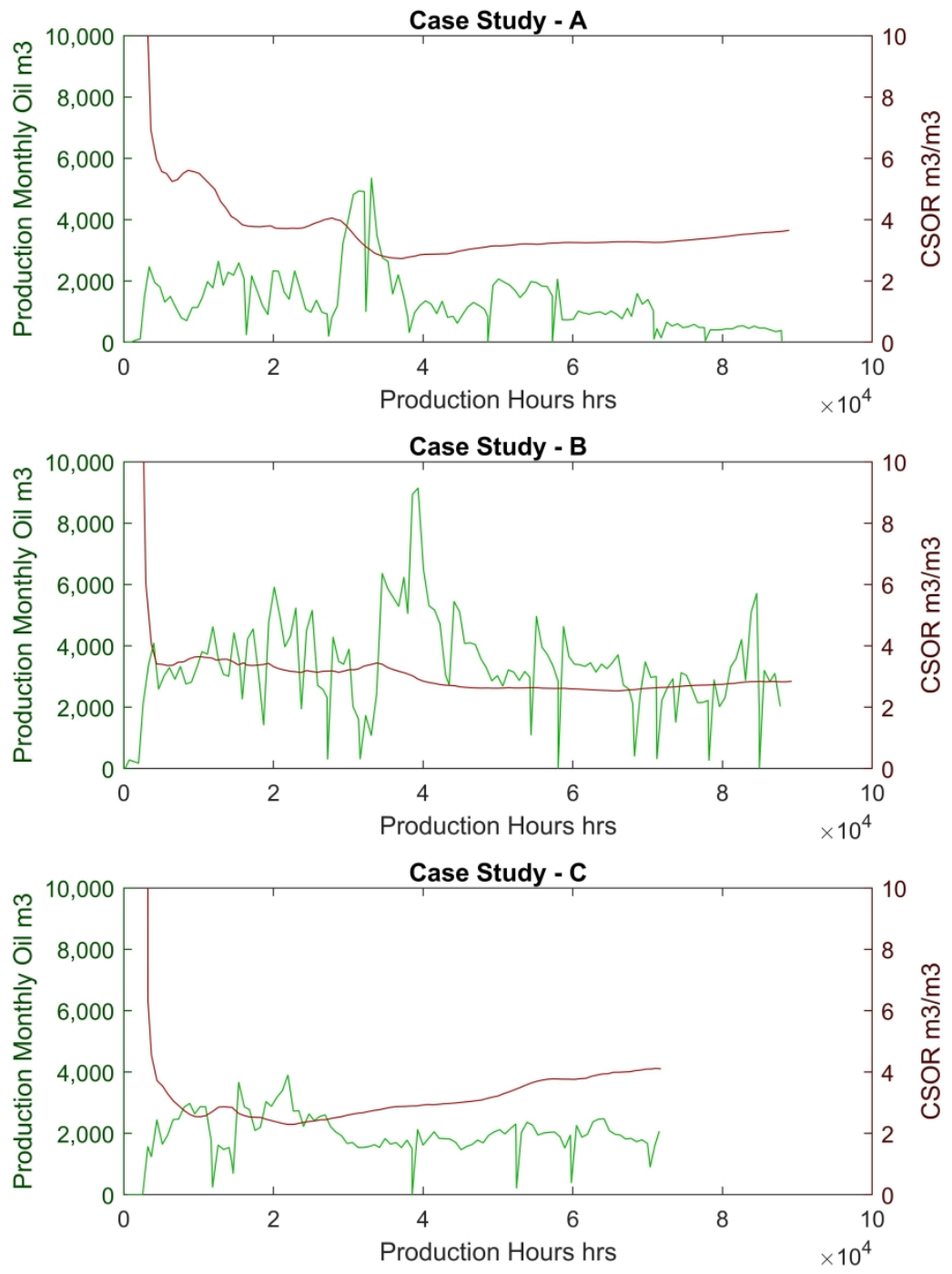

Figure 4 - Oil production and cumulative steam oil ratio for different case studies.

$1234 \times 1816 \mathrm{~mm}(72 \times 72 \mathrm{DPI})$ 
Figure 5 - Overlay of subsurface velocity profile and high-resolution SWD image corresponding to the crosssection represented in Figure-3. Black arrows highlight the boundary between reservoir-quality facies and mudstone. 
Figure 6 - Vertical reservoir cross section along Case B well pair. Different colors define different zones (i.e., roughly equivalent to depositonal elements) in the model, with GR logs shown along the laterals. The horizontal scale is $1: 2800$, and the vertical exaggeration is 4.5 .

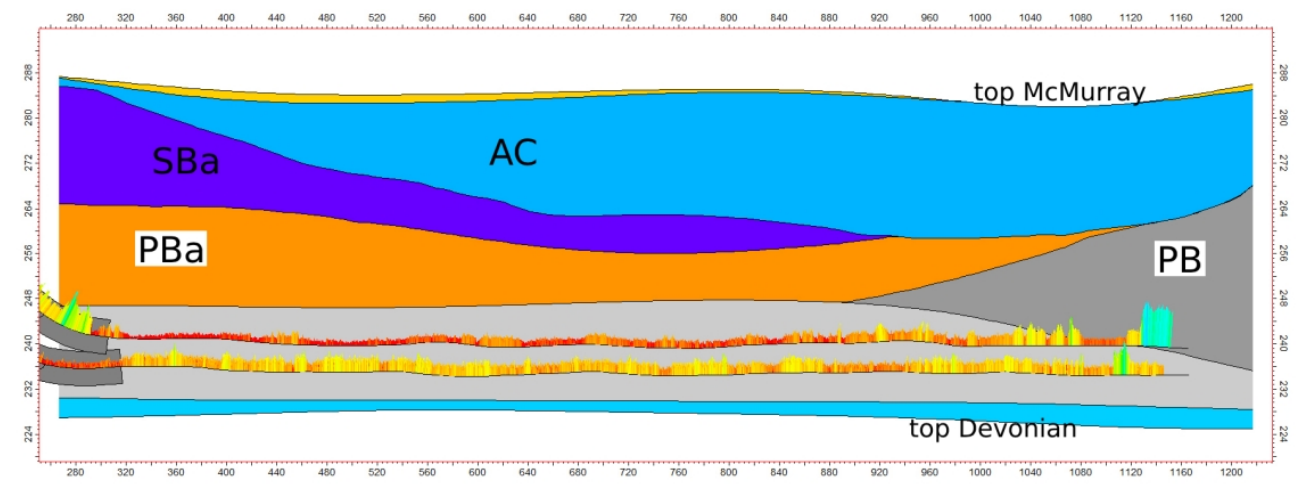


Figure 7 - Vertical reservoir cross section along Case C well pair. Different colors define different zones (i.e., roughly equivalent to depositonal elements) in the model, with GR logs shown along the laterals. The horizontal scale is 1:2800, and the vertical exaggeration is 4.5 . 
Figure 8 - A) Seismic-depth cross section of the McMurray Formation in the study area. B) Line trace showing the elements of meander-belt deposits at different stratigraphic levels. 3D seismic resolution is relatively poor up to $10 \mathrm{~m}$ above the unconformity. (Modified from Durkin et al. 2017)

\author{
$1023 \times 693 \mathrm{~mm}(72 \times 72 \mathrm{DPI})$
}




\begin{tabular}{|c|c|c|c|c|}
\hline Case & Producer Length & Injector Length $(\mathrm{m})$ & Monthly Oil $\left(\mathrm{m}^{3}\right)$ & $\mathrm{CSOR}\left(\mathrm{m}^{3} / \mathrm{m}^{3}\right)$ \\
\hline A & $850(140 \mathrm{~m}$ Mudstone $)$ & 710 & 1,400 & 3.6 \\
\hline B & 860 & 860 & 3,600 & 2.8 \\
\hline C & $840(463 \mathrm{~m}$ IHS $)$ & 840 & 2,100 & 4.1 \\
\hline Pad Average & 850 & 850 & 2,700 & 3.4 \\
\hline
\end{tabular}


Copyright $(C) 2020$ Society of Petroleum Engineers

Original SPE manuscript received for review 29 January 2020. Revised manuscript received for review 18 May 2020.

Paper (SPE 199931) peer approved 27 May 2020. 